\title{
Primary Medical Care in the United Kingdom
}

\author{
Martin Roland, DM, Bruce Guthrie, MB, BChir, PhD, and \\ David Colin Thomé, MB, BS
}

\begin{abstract}
Since 1948 health care in the United Kingdom (UK) has been centrally funded through the National Health Service (NHS). The NHS provides both primary and specialist health care which is largely free at the point of delivery. Family practitioners are responsible for registered populations of patients and typically work in groups of 4-6 self-employed physicians. They hire nurses and a range of other ancillary staff, and act as gatekeepers to specialist care. Recent reforms include a wide range of national quality improvement initiatives and a pay for performance scheme that accounts for around $25 \%$ of family practitioners' income. These reforms have been associated with some major improvements in quality, including improved chronic disease management and reduced waiting times for specialist care. The four countries of the UK differ in some important aspects of health care organization: proposed reforms in England would move towards a more market-driven system, with family practitioners acting as payers for specialist care and controlling $\mathbf{7 0 \%}$ of the NHS budget. The other countries (Scotland, Wales and Northern Ireland) focus more on trying to create area-based integrated systems of care. ( $\mathrm{J}$ Am Board Fam Med 2012;25:S6-11.)
\end{abstract}

Keywords: Health Care Services, Health Care Systems, Health Policy, Primary Health Care, United Kingdom

\section{Primary Care Models and Payment Systems}

Core features of UK primary care have been constant since the National Health Service (NHS) was created in 1948. There is universal registration with a single practice of the patient's choice, and all primary medical care is provided by general practitioners (GPs), which are broadly equivalent to US

This article was externally peer reviewed.

Submitted 26 June 2011; revised 1 November 2011; accepted 21 November 2011.

From the Department of Health Services Research, University of Cambridge, Institute of Public Health, Cambridge, England, United Kingdom (MR); Department of Primary Care, Population Health Sciences Division, University of Dundee, Dundee, Scotland, United Kingdom (BG); and Primary Care Independent Consultant, Eshott, Morpeth, and Northumberland, England, United Kingdom (DCT).

Funding: none.

Prior presentation: This article was written as a contribution to an international meeting on the future of primary care in April 2011, convened by the American Association of Family Practice and generously funded by the Agency for Healthcare Quality and Research.

Conflict of interest: Dr Colin Thomé was Primary Care Adviser to the Department of Health during some of the reforms described in this article.

Corresponding author: Martin Roland, DM, Health Services Research, University of Cambridge, Institute of Public Health, Robinson Way, Cambridge CB2 0SR (E-mail: mr108@ cam.ac.uk). family physicians. Primary and specialist care is almost entirely free at the point of delivery and is funded nationally from general taxation; however, there are outpatient prescription charges of $£ 7.20$ (US\$11.60) per item in England, $\$ 3.00$ (US\$4.80) in Scotland, but there are no prescription charges in Wales. Approximately $90 \%$ of items are dispensed to people who are exempt from prescription charges. There are additional charges for dental care and care provided by opticians. There is a strict divide between primary and specialist care: specialists work largely in hospitals, where they provide inpatient care for all and see new and follow-up patients in clinics, whereas GPs act as gatekeepers to specialists with some small exceptions, including attendance at the emergency department and sexual health service. GPs work in practices, which they usually own, in partnerships of 4 to 6 physicians, on average. These practices derive the great majority of their income from contracts to provide NHS patient care. Under these contracts, approximately $75 \%$ of practice income comes from capitation, 20\% from pay-for-performance (P4P) fees under the Quality and Outcomes Framework (QOF), and 5\% from Enhanced Services' contracts 
for more specialist care (for example, services for those who misuse substances). Using this income, GPs employ staff in any configuration they wish; GPs' take-home pay is the practice's profit. Currently, the average net pay of a GP is slightly more than the average NHS income of a specialist.

\section{Infrastructure}

Workforce and Patterns of Work

General practices remain small, physician-owned businesses, but there have been significant changes over the last 20 years. Practices have grown from an average size of 5726 patients in 2000 to $6610 \mathrm{pa}$ tients in 2010, with the proportion of solo practices falling from $22.8 \%$ to $14.5 \%$ and the average patient panel per GP falling from 1795 to 1567 over the same period. ${ }^{1}$ There has been a steady increase in nurses employed by GPs and more recent shifts to existing partners employing lower-paid but salaried physicians rather than taking on new profitsharing partners. Nurses are able to substitute for GPs in many aspects of primary care without a loss of quality, ${ }^{2}$ and the increasing use of nurses in chronic disease management has been associated with improvements in quality of care. ${ }^{3}$ A typical practice team might now consist of 5 or 6 GPs, one nurse practitioner, 2 or 3 practice nurses, and between 6 and 10 receptionists/administrative staff. In addition, practices work closely with a broader, often co-located primary health care team that is employed directly by the NHS. This wider team may include district nurses, who providing home nursing care; health visitors, who provide wellchild care; and more variably midwives, community psychiatric nurses, and allied health professionals. Much less commonly, practices have social workers embedded in their team.

UK primary care is primarily provided through face-to-face consultation on the practice premises with home visits available for those who are unable to travel. In the last 15 years there has been an increase in consultation rates, an increase in the proportion of patients seen by nurses, an increase in phone consultations, and a reduced number of home visits. In parallel, there has been an increase in the length of GP consultations (Table 1). ${ }^{4}$ GPs retain a gatekeeping role, although the speed of access to specialists has improved in recent years, with $80 \%$ of patients now getting to see a specialist within 4 weeks compared with $88 \%$ in the United States. $^{5}$
Table 1. United Kingdom General Practice Consultations, 1995 to $2008^{40}$

\begin{tabular}{lcc}
\hline & 1995 & 2008 \\
\hline Consultation rate per person registered & 3.9 & 5.5 \\
Clinician consulted (\%) & 76 & 62 \\
GP & 21 & 34 \\
Practice nurse & 3 & 4 \\
Other & & \\
Place of consultation (\%) & 86 & 82 \\
Practice premises & 9 & 4 \\
Home visit & 3 & 12 \\
Phone & 2 & 3 \\
Other & & \\
Average length of consultation (min) & \\
GP & 8.4 & 11.7 \\
Practice nurse & NA & 15.5 \\
\hline
\end{tabular}

*Data for March 1992 and June 2006. ${ }^{41}$

GP, general practitioner; NA, not available.

\section{Information Technology}

In 1990, the introduction of payments for reaching cervical cytology and immunization targets required GPs to establish recall mechanisms. Many responded by buying computer systems; this was facilitated by the NHS, which covered $50 \%$ of the costs if the systems met government-defined standards. By the end of the decade, most GPs were using computers to print prescriptions and a substantial minority had made their own clinical record fully electronic. In 2004, the data requirements of QOF P4P system led most GPs to move to full electronic clinical records. The government at that time also moved to cover the full cost of GP computer systems. Because GP payment has virtually no fee-for-service element, clinical computer systems have been designed for clinical purposes and to measure quality rather than for billing. Many practices have now moved to fully paperless records. Because records follow the patient when they change practices and specialists routinely write to GPs after a visit or admission, primary care records, in principle, contain a lifelong record of patient's medical care.

\section{Area-Based Primary Care Organization}

GPs are accountable for the care they provide through the contract they hold with the NHS. Local NHS administrative organizations, currently Primary Care Trusts in England and Health Boards in Scotland, have the responsibility for im- 
plementing national policy, monitoring practices, and implementing local quality improvement and financial incentive schemes. Prescribing is an example of an area in which there has been longstanding engagement between practices and larger NHS organizations, starting with feedback of comparative prescribing cost data, which developed into regular educational outreach visits by prescribing advisers, and the creation and more recently incentivization of local prescribing indicators. In England, these organizations are subject to frequent politically driven reorganization that causes repeated disruption; this is sometimes termed redisorganization. ${ }^{6,7}$

\section{Creating and Sustaining Change/Transformation}

Change in primary care continues to rely significantly on the entrepreneurialism and professionalism of GPs, although with the support and leadership from professional organizations such as the Royal College of GPs, which has historically led primary care standard setting and quality accreditation schemes. However, system-wide change is usually driven by national policy. Despite overall high standards, the gap between the least and most progressive practices remains wide. There are good examples of successful improvement in quality (refer to Quality and Safety), but 2 areas that have proved persistently problematic are out-of-hours $(\mathrm{OOH})$ care and improving care coordination.

\section{Out-of-Hours Care}

Until 2004, GPs had 24-hour responsibility for the care of their registered patients. $\mathrm{OOH}$ care was at that time largely delivered by area-based cooperatives of GPs, which provided $\mathrm{OOH}$ care mainly through home visits. In 2004, the local NHS administrative organizations took over responsibility for $\mathrm{OOH}$ care. They most often contracted care to a commercial organization (sometimes run by local GPs) that employed doctors and an increasing number of nurses and that progressively provided care at purpose-built facilities rather than at the patient's home. There has been considerable disquiet over the standard of $\mathrm{OOH}$ care under these new arrangements, ${ }^{8}$ particularly in England, where responsibility for $\mathrm{OOH}$ care will return to GP leadership in 2013, albeit as the responsibility of Commissioning Consortia rather than individual practices.

\section{Care Coordination}

In principle, GPs are responsible for coordinating the care of individual patients, which is facilitated by their gatekeeper role and by having a comprehensive patient record. International surveys suggest that UK primary care is rated high by patients in terms of coordination, ${ }^{9}$ but existing models of care do not always meet the needs of the increasing number of elderly, comorbid, and frail patients in the community. In response, policy has created new services for patients who are at particularly high risk of hospitalization, including the development of predictive risk models to identify patients for intensive case management (by "community matrons" in England). However, the evidence that these new services are effective is weak; continuity of care becomes more difficult as teams get larger ${ }^{10}$ and there is a tension between providing rapid access and personal continuity of care. ${ }^{11}$ Integration across primary-secondary care and health-social care boundaries, and addressing the needs of increasingly elderly and comorbid populations, remain significant challenges.

\section{Quality and Safety}

\section{Quality Improvement Initiatives (Including P4P)}

In 1990, the United Kingdom introduced modest $\mathrm{P} 4 \mathrm{P}$ in primary care in the form of payments for reaching target levels of childhood immunization and cervical cytology. This led to increased performance followed by a slower reduction in socioeconomic inequalities. ${ }^{12,13}$ In 1998, the NHS embarked on a widespread program of quality improvement under the general heading of "clinical governance." ${ }^{14-16}$ This included the development of national clinical guidelines and national service frameworks to guide implementation of improvement activity; a body to make recommendations about cost-effective treatments in England (NICE, www.nice.nhs.uk); the introduction of annual appraisal for all NHS doctors; district-wide audits of clinical care, with identifiable data being shared with practices and sometimes with patients; and a range of local financial incentives schemes for quality improvement. These were associated with significant improvements in quality of care. ${ }^{17}$

In 2004, a new and much more ambitious P4P scheme was introduced in general practice, with $20 \%$ to $25 \%$ of GPs' income dependent on a complex set of $\sim 75$ indicators relating to clinical care 
and 75 relating to practice organization and patient experience (the QOF). ${ }^{18}$ Since 2004, new clinical topics have been introduced and payment thresholds have been raised gradually. An important feature of QOF is that GPs can exclude patients if they judge that incentivized care would be inappropriate for particular individuals. ${ }^{19}$ A scheme to tie GP payments directly to patient experience survey scores was introduced in 2008, but it proved problematic $^{20}$ and was withdrawn in 2011. In general, QOF financial incentives have produced some increase in the rate of quality improvement for major chronic diseases, but this against a background of quality that was already improving rapidly. ${ }^{21}$ The introduction of QOF has been associated with reduced socioeconomic inequalities in the delivery of care $^{22}$ and may in some cases have helped to reduce emergency hospital admissions. Public reporting of QOF results is likely to have contributed to quality improvements alongside financial incentives, and these were probably larger than they needed to be. $\mathrm{P} 4 \mathrm{P}$ has changed both the organization of practices and relationships within them, ${ }^{23-26}$ and it has changed care in ways that sometimes have been unfamiliar to and unwelcomed by physicians. ${ }^{27}$ Measured negative impacts on nonincentivized conditions seem to have been small, ${ }^{28-30}$ but critics believe that QOF has introduced a negative "tick box" culture into primary care. ${ }^{31}$ Despite recent improvements, there remains a substantial gap between the best and the poorest practices and a range of areas where quality could still be improved. $^{32}$

\section{Commissioning in a Health Care Market and Its Alternatives}

Under proposals to be implemented in England by 2013, consortia of general practices (Clinical Commissioning Consortia) will be given control of two thirds of the entire NHS budget for specialist and hospital care for their patients, ${ }^{33}$ though the original proposals are to be modified as a result of professional and public concern. ${ }^{34}$ The government's rationale for giving GPs such power is that they have responsibility for defined populations and are therefore the best placed to identify and meet those populations' needs. This builds on previous experiments that gave GPs budgets to purchase hospital care (GP fundholding), which had some modest benefit although it may also have increased inequalities. ${ }^{35-37}$ In contrast to NHS
England's reliance on quasimarket mechanisms and strongly managed, centrally set targets to drive improvements in quality, the other 3 UK countries (Scotland, Wales, Northern Ireland) have chosen to focus on trying to create more integrated, areabased "single system working," which relies on encouraging professionally led collaboration. ${ }^{38}$ The reforms in England remain highly controversial, partly because of the expanded role given to GPs with potential conflicts of interest between their twin roles as care providers and budget holders, and partly because of the increased opportunities for the commercial health care sector that the reforms introduce. It remains unclear which approach will deliver the best outcomes in the long run, but in all UK countries, past and present governments remain committed to keeping primary care central to the delivery of care in the NHS.

\section{Key Lessons}

The United Kingdom has health outcomes that are broadly comparable with other, more costly health care systems. There are, however, some areas of continuing concern, including mortality for conditions that are considered amenable to health care and for which the United Kingdom performs worse than many other European countries (though similar to the United States) and outcomes of cancer care. ${ }^{39}$ The NHS is generally highly regarded by the British public, who are largely accepting of the GPs gatekeeping role and surprisingly tolerant of system failures when they occur. Primary care remains at the heart of successive governments' health care policies. The core strengths of UK primary care remain universal registration with a primary care practitioner, relatively good access to primary care in terms of both distribution of GPs and speed of access, gatekeeping to specialist care, lifelong primary care records that follow the patient when they move practices and that are now almost always electronic, and care that is mostly free at the point of delivery. That primary care practitioners have responsibility for a defined population enables them to be held accountable for the quality of care they provide. Quality of care in the United Kingdom has improved substantially in the last 10 years, most evidently in chronic disease management, which has been associated with multiple quality improvement strategies, including P4P. Nevertheless, as with all health care systems, there remain many challenges, 
including providing comprehensive care with and continuity of care by a workforce that is increasingly part time. This is because of an increase in the number of both men and women who work part time and to the increasing size of general practices. At the same time, the need for continuous comprehensive care is increasing with a growing elderly population with multiple medical conditions.

\section{References}

1. NHS Information Centre. General and Personal Medical Services England 2000-2010. Leeds: NHS Information Centre; 2010. Available at http://www. ic.nhs.uk/webfiles/publications/010_Workforce/ nhsstaff0010/GP/General_Practice_Bulletin_ 2000-2010.pdf

2. Laurent M, Reeves D, Hermens R, Braspenning J, Grol R, Sibbald B. Substitution of doctors by nurses in primary care. Cochrane Database Syst Rev 2005; (2):CD001271.

3. Griffiths P, Murrells T, Maben J, Jones S, Ashworth M. Nurse staffing and quality of care in UK general practice. Br J Gen Pract 2010;60:36-48.

4. NHS Information Centre. 2006/07 UK General Practice Workload Survey. Leeds: NHS Information Centre; 2007. Available at http://www.ic.nhs.uk/ statistics-and-data-collections/primary-care/generalpractice/gp-workload-survey. Accessed January 27, 2012.

5. Schoen C, Osborn R, Squires D, Doty M, Pierson R, Applebaum S. 2011 Commonwealth Fund International Health Policy Survey. Available at www. commonwealthfund.org/Surveys/2011/Nov/2011International-Survey.aspx. Accessed February 1, 2012.

6. Smith J, Walshe K, Hunter D. The redisorganisation of the NHS. BMJ 2001;323:1262-3.

7. Oxman A, Sackett D, Chalmers I, Prescott T. A surrealistic meta-analysis of redisorganization theories. J R Soc Med 2005;98:563-8.

8. Richards S, Pound P, Dickens A, Greco M, Campbell J. Exploring users' experiences of accessing outof-hours primary medical care services. Qual Saf Health Care 2007;16:469-77.

9. The Commonwealth Fund. All surveys. Available at http://www.commonwealthfund.org/Surveys/ViewAll.aspx. Accessed January 27, 2012.

10. Wagner E, Reid R. Are continuity of care and teamwork incompatible? Med Care 2007;45:6-7.

11. Guthrie B, Wyke S. Personal continuity and access in UK general practice: a qualitative study of general practitioners' and patients' perceptions of when and how they matter. BMC Fam Pract 2006;7:11.

12. Baker D, Middleton E. Cervical screening and health inequality in England in the 1990s. J Epidemiol Community Health 2003;57:417-23.
13. Middleton E, Baker J. Comparison of social distribution of immunisation with measles, mumps, and rubella vaccine, England, 1991-2001. BMJ 2003; 326:854.

14. UK Department of Health. Publications policy and guidance. A first class service: quality in the new NHS. July 1998. Available at www.dh.gov.uk/en/ Publicationsandstatistics/Publications/Publications PolicyAndGuidance/DH_4006902. Accessed February 28, 2011.

15. Buetow S, Roland M. Clinical governance: bridging the gap between managerial and clinical approaches to quality of care. Qual Health Care 1999;8:184-90.

16. Campbell SM, Sheaff R, Sibbald B, et al. Implementing clinical governance in English primary care groups/ trusts: reconciling quality improvement and quality assurance. Qual Saf Health Care 2002;11:9-14.

17. Campbell SM, Roland MO, Middleton E, Reeves D. Improvements in the quality of clinical care in English general practice 1998-2003: longitudinal observational study BMJ 2005;331:1121-5.

18. Roland M. Linking physician pay to quality of care: a major experiment in the UK. N Engl J Med 2004; 351:1448-54.

19. Doran T, Fullwood C, Reeves D, Gravelle H, Roland M. Should physicians be able to exclude individual patients from pay-for-performance targets? Analysis of exception reporting in the English payfor-performance scheme. N Engl J Med 2008;359: 274-84.

20. Roland M, Elliott M, Lyratzopoulos G, et al. Reliability of patient responses in pay for performance schemes: analysis of national General Practitioner Patient Survey data in England. BMJ 2009;339: b3851.

21. Campbell SM, Reeves D, Kontopantelis E, Sibbald B, Roland M. Effects of pay-for-performance on the quality of primary care in England. N Engl J Med 2009;361:368-78.

22. Doran T, Fullwood C, Kontopantelis E, Reeves D. Effect of financial incentives on inequalities in the delivery of primary clinical care in England: analysis of clinical activity indicators for the quality and outcomes framework. Lancet 2008;372:728-36.

23. Grant S, Huby G, Watkins F, et al. The impact of pay-for-performance on professional boundaries in UK general practice: an ethnographic study. Sociol Health Illn 2009;31:229-45.

24. McDonald R, Harrison S, Checkland K, Campbell, SM, Roland M. Impact of financial incentives on clinical autonomy and internal motivation in primary care: ethnographic study. BMJ 2007;334: 1357-9.

25. McDonald R, Checkland K, Harrison S, Coleman A. Rethinking collegiality: restratification in English general medical practice 2004-2008. Soc Sci Med 2009;68:1199-205. 
26. Checkland K, Harrison S. The impact of the Quality and Outcomes Framework on practice organisation and service delivery: summary of evidence from two qualitative studies. Qual Prim Care 2010;18:139-46.

27. Leydon GM, Dowrick CF, McBride AS, et al. Questionnaire severity measures for depression: a threat to the doctor-patient relationship? Br J Gen Pract 2011;61:117-23.

28. Steel N, Maisey S, Clark A, Fleetcroft R, Howe A. Quality of clinical primary care and targeted incentive payments: an observational study. $\mathrm{Br} \mathrm{J}$ Gen Pract 2007;57:449-54.

29. Doran T, Kontopantelis E, Valderas J, et al. Effect of financial incentives on incentivised and non-incentivised clinical activities: longitudinal analysis of data from the UK Quality and Outcomes Framework. BMJ 2011;342:d3590.

30. Dusheiko M, Doran T, Gravelle H, Fullwood C, Roland M. Does higher quality of diabetes management in family practice reduce unplanned hospital admissions? Health Serv Res 2011;46(1 Pt 1):27-46.

31. Mangin D, Toop L. The Quality and Outcomes Framework: what have you done to yourselves? Br J Gen Pract 2007;57:435-7.

32. The King's Fund. Improving the quality of care in general practice: report of an independent inquiry commissioned by The King's Fund. Updated April 2011. Available at www.kingsfund.org.uk/publications/ gp_inquiry_report.html. Accessed January 27, 2012.

33. Roland M, Rosen R. Healthcare reform: the English NHS embarks on controversial and risky market style reforms. N Engl J Med 2011;364:1360-6.

34. UK Department of Health. Government response to the NHS Future Forum report. June 2011. Available at www.dh.gov.uk/prod_consum_dh/groups/dh digitalassets/documents/digitalasset/dh_127719.pdf. Accessed January 27, 2012.
35. Wyke S, Mays N, Street A, Bevan G, McLeod H, Goodwin N. Should general practitioners purchase health care for their patients? The total purchasing experiment in Britain. Health Policy 2003;65:243-59.

36. Smith J, Mays N, Dixon J, et al. A review of the effectiveness of primary care-led commissioning and its place in the NHS health foundation. 2004. Available at www.health.org.uk/publications/research_ reports/effectiveness_nhs.html. Accessed January 27, 2012.

37. Harrison S, Checkland K, Coleman A. Practicebased commissioning in the English National Health Service: evidence and prospects. In: House of Commons Health Committee. Commissioning: fourth report of session 2009-10. Volume 2: oral and written evidence. London: The Stationery Office Limited; 2010:86-90. Available at www.publications. parliament.uk/pa/cm200910/cmselect/cmhealth/268/ 268ii.pdf. Accessed January 27, 2012.

38. Greer SL. Four way bet: how devolution has led to four different models for the NHS. London: University College London, Constitution Unit; 2004.

39. Nolte E. International benchmarking of healthcare quality: a review of the literature. 2010. Available at www.rand.org/content/dam/rand/pubs/technical_ reports/2010/RAND_TR738.pdf. Accessed January 27, 2012.

40. Hippisley-Cox J, Vinogradova Y. Trends in consultation rates in general practice 1995 to 2008: analysis of the QResearch database. Leeds: NHS Information Centre; 2009. Available at http://www.ic.nhs.uk/ webfiles/publications/gp/Trends_in_Consultation_ Rates_in_General_Practice_1995_2008.pdf. Accessed February 1, 2012.

41. NHS Information Centre. GP workload survey. July 2007, Available at http://www.ic.nhs.uk/webfiles/ publications/gp/GP\%20Workload\%20Report.pdf. Accessed January 27, 2012. 